\title{
Comparative Evaluation of Surface Microhardness of Artificially Demineralized Human Enamel with Nano Hydroxyapatite, Calcium Phosphate, and Potassium Nitrate Remineralizing Agents: An In Vitro Study
}

\author{
${ }^{1}$ Priya Madhusudanan, ${ }^{2}$ Praveena SV, ${ }^{3}$ Rajesh Pillai, ${ }^{4}$ Nettiyat O Varghese, ${ }^{5}$ Sheila George, ${ }^{6}$ Abe Antony
}

\begin{abstract}
Aim: To evaluate and compare the microhardness of artificially demineralized human enamel treated with three different remineralizing agents.
\end{abstract}

Materials and methods: Twenty-five intact caries free maxillary premolar were taken for the study. The tooth was decoronated $2 \mathrm{~mm}$ below cementoenamel junction (CEJ). Enamel samples of $2 \mathrm{~mm}$ width were prepared, the enamel slices were taken from the buccal and lingual surfaces of the teeth using a diamond disc. Following sample preparation, windows were created with a dimension of $5 \mathrm{~mm} \times 5 \mathrm{~mm}$. Adhesive tape was placed over it to resist acid attack. The specimens were demineralized using a demineralizing solution for ten days and then subjected to microhardness testing. Teeth were divided into five groups.

- Group 1: Negative control in which no therapy was done

- Group 2: Demineralized enamel specimen

- Group 3: Remineralization with potassium nitrate containing toothpaste

- Group 4: Remineralization with casein phosphopeptide-amorphous calcium phosphate (CPP-ACP) containing toothpaste,

- Group 5: Remineralization with hydroxyapatite containing toothpaste. The remineralizing agents were applied using cotton applicator tips for 3 minutes twice daily and they were washed under distilled water. The samples were then stored in artificial saliva for 10 days and subjected to microhardness testing.

Statistical analysis: One-way analysis of variance (ANOVA) test. A post hoc comparison showed that done using a paired t-test.

Results: The result showed that there has been statistically significant difference in the microhardness for control samples and experimental samples. Within the experimental samples, group which used hydroxyapatite paste as remineralizing paste showed better results when compared to paste which contain calcium and potassium ions and sodium nitrate.

\footnotetext{
${ }^{1,2}$ Postgraduate Student, ${ }^{3}$ Professor and HOD, ${ }^{4}$ Professor and Principal, ${ }^{5}$ Professor, ${ }^{6}$ Senior Lecturer

1-6Department of Conservative and Endodontics, PMS Dental College of Science and Research, Thiruvananthapuram, Kerala, India

Corresponding Author: Priya Madhusudanan, Postgraduate Student, Department of Conservative and Endodontics, PMS Dental College of Science and Research, Thiruvananthapuram, Kerala, India, e-mail: priya_madhu_raja@yahoo.co.uk
}

Keywords: Dental caries, Microhardness, Remineralizing agents.

How to cite this article: Madhusudanan P, Praveena SV, Pillai R, Varghese NO, George S, Antony A. Comparative Evaluation of Surface Microhardness of Artificially Demineralized Human Enamel with Nano Hydroxyapatite, Calcium Phosphate, and Potassium Nitrate Remineralizing Agents: An In Vitro Study. Cons Dent Endod J 2018;3(2):50-55.

Source of support: Nil

Conflict of interest: None

\section{INTRODUCTION}

An ounce of prevention is worth a pound of cure!!

Dental caries is the most common disease affecting a large number of communities. Dental caries is a process that takes place on any tooth surface where the dental plaque is accumulated for a long period. ${ }^{1}$ The occurrence of caries is dependent on the $\mathrm{pH}$ of saliva. Enamel dissolution starts when the $\mathrm{pH}$ drops below 5.5, thus initiating demineralization. It marks the beginning of early enamel caries as well. During repeated falls in $\mathrm{pH}$, the subsurface layer gets demineralized while the enamel surface layer stays consistently unmutilated. ${ }^{2}$ Neutralizing the oral $\mathrm{pH}$ opposes the process of demineralization. ${ }^{3}$ This can be achieved by intensifying calcium and phosphate ions supply. This process is called as remineralization, which involves the rebuilding of partly dissolved apatite crystals. Demineralization is naturally reversed to remineralization by incorporation of minerals from saliva into the lesion. ${ }^{4}$

The emphasis on caries management has been recently modified with the development of strategies for early detection of caries lesions and the practice of non-invasive treatment for these lesions. ${ }^{5}$ Various remineralization agents have been introduced to enhance this mechanism. Numerous mechanisms are available for accelerated remineralization. This demands the availability of calcium and phosphate along with fluoride ions to rebuild a new surface on existing affected structure. It involves a delivery mechanism of ions to the affected area mainly the subsurface lesion area than merely on the surface. Topical fluorides have been well known and proven as a 
delivery system for the prevention of caries. ${ }^{6}$ Restriction of initiation of dental caries can be achieved by milk and its products. Casein, calcium, and phosphate provide this anti-cariogenic property to milk, imparting its protective action. ${ }^{7,8}$ Recently, hydroxyapatite was introduced as a promising remineralizing agent. ${ }^{6-8}$

To date, no study has compared the remineralization potential of hydroxyapatite (Aclaim), CPP-ACP), GC Tooth Mousse, Leuven, Belgium) and Potassium nitrate ( $\mathrm{KNO}_{3}$, Colgate sensitive clove oil). Therefore, the present in vitro study was designed to assess and compare the remineralizing capacity of the above agents on artificial enamel lesions, through Vicker's microhardness testing.

\section{MATERIALS AND METHODS}

Twenty-five freshly extracted sound maxillary premolars, extracted for therapeutic reasons, were used. Teeth with any caries or white spot lesions were excluded (Fig. 1). The teeth were decoronated and the crown portions were divided into two segments of one buccal and one palatal half using a diamond disc mounted on a contra-angle

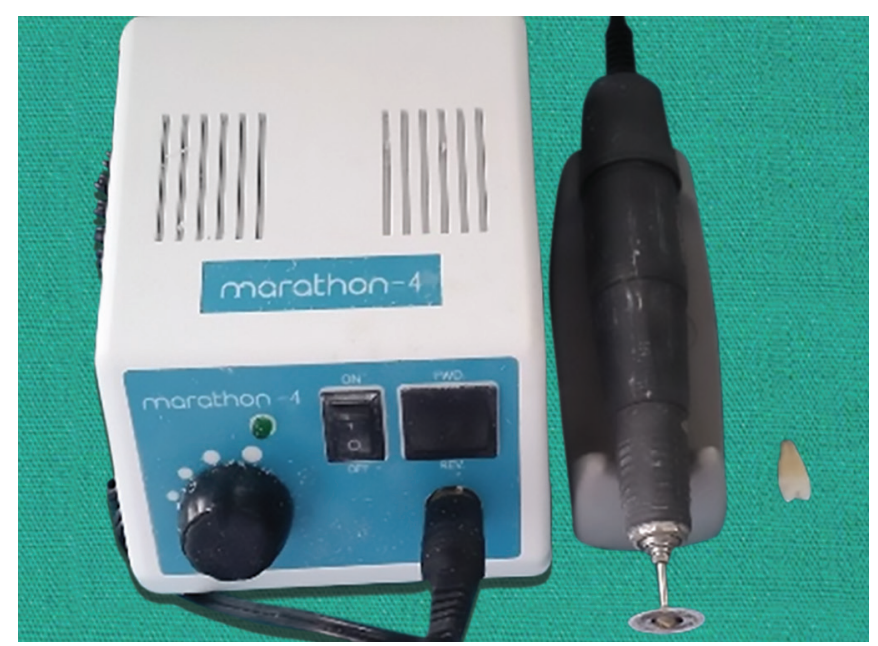

Fig. 1: Sectioning of tooth

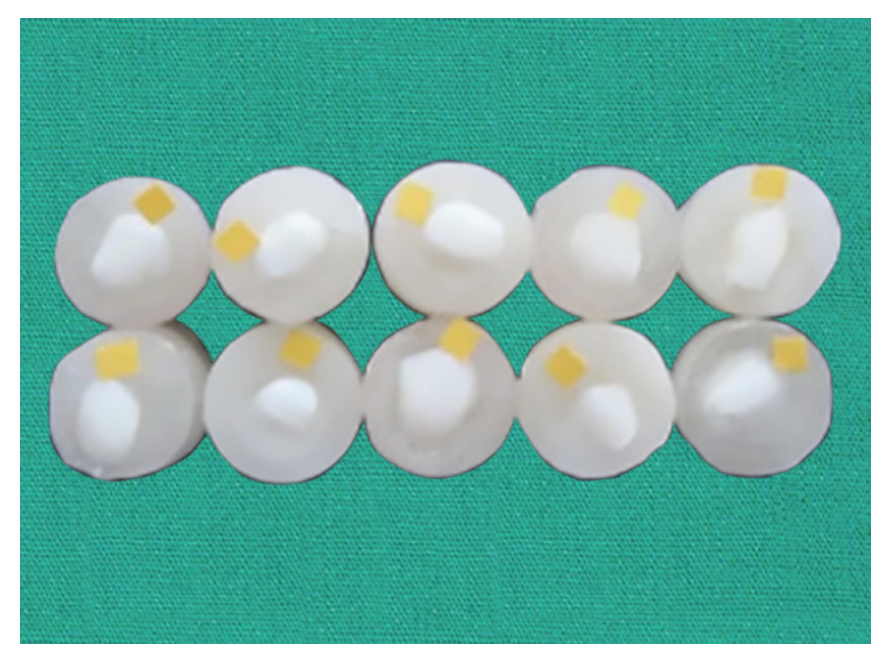

Fig. 3: Demineralized enamel specimen handpiece. Enamel samples were fixed on the self-cure acrylic mold with the enamel surface exposed. These samples were stored in deionized water until further use. A total of fifty enamel samples embedded in partially set acrylic cylinders were produced and then they were randomly divided into five groups of 10 samples each.

- Group 1: Negative control in which no therapy was done (Fig. 2)

- Group 2: Demineralized enamel specimens (Fig. 3)

- Group 3: Potassium nitrate containing toothpaste (Fig. 4)

- Group 4: CCP-ACP containing toothpaste (Fig. 5)

- Group 5: Hydroxyapatite containing toothpaste (Fig. 6) The demineralizing solution was prepared in the Department of Biochemistry. ${ }^{9}$ The $\mathrm{pH}$ of the demineralizing solution was checked during and after preparation of solution using digital $\mathrm{pH}$ meter. The composition of the demineralizing solution used was as follows:

- $2.2 \mathrm{mM}$ calcium chloride, $\mathrm{CaCl}_{2} \cdot 2 \mathrm{H}_{2} \mathrm{O}$

- $2.2 \mathrm{mM}$ monosodium phosphate, $\mathrm{NaH}_{2} \mathrm{PO}_{4} \cdot 7 \mathrm{H}_{2} \mathrm{O}$

- $0.05 \mathrm{M}$ lactic acid, $\mathrm{C}_{3} \mathrm{H}_{6} \mathrm{O}_{3}$

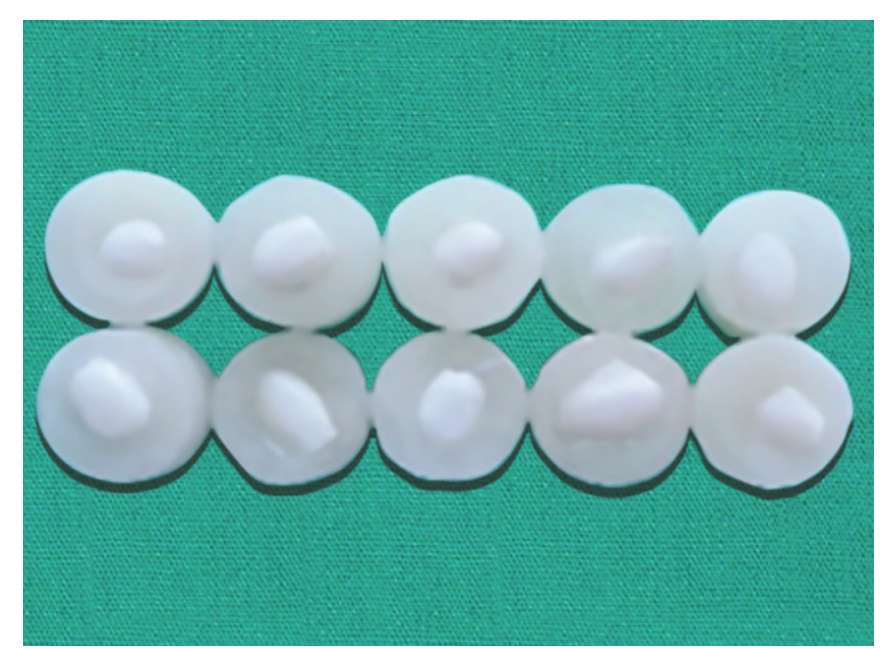

Fig. 2: Negative control

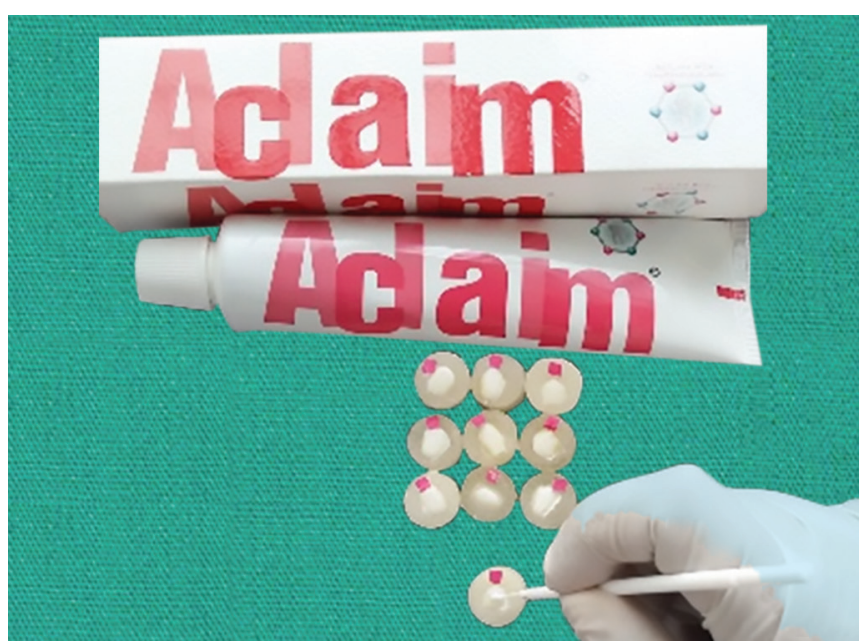

Fig. 4: Remineralization with Hydroxyapatite paste 


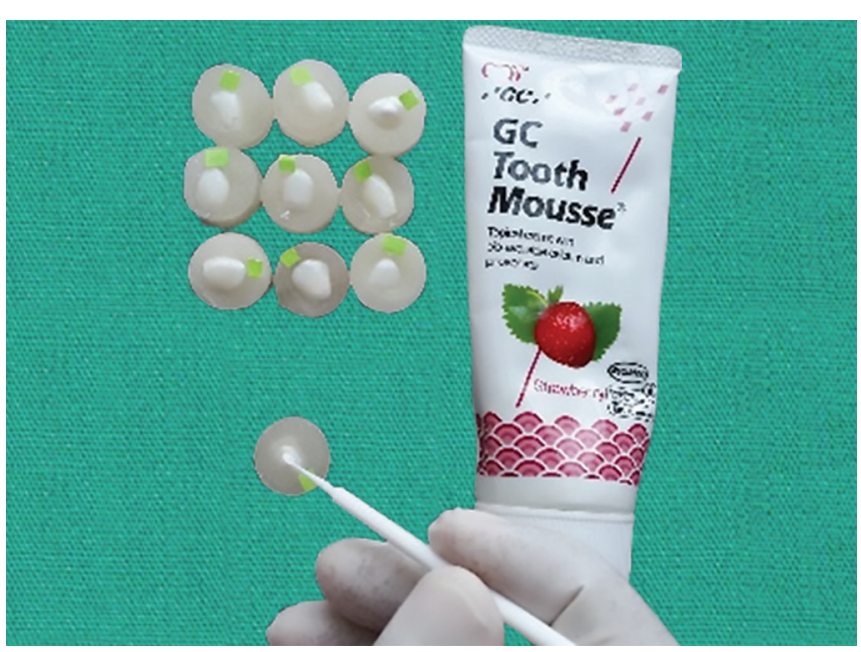

Fig. 5: Remineralization with CCP-ACP paste

The final $\mathrm{pH}$ was adjusted to 4.5 with $50 \%$ sodium hydroxide, $\mathrm{NaOH}$. All the samples except group 1 were then immersed into a glass container containing $50 \mathrm{~mL}$ of prepared demineralizing solution for a period of $6 \mathrm{~h}$ at $37^{\circ} \mathrm{C}$. This demineralizing procedure was considered to produce a consistent subsurface enamel lesion in all samples. ${ }^{10}$ After demineralization, the teeth were washed with deionized water and dried.

The samples in groups 3 to 5 were treated with respective remineralizing agents for 3 minutes twice daily for 10 days $^{11}$ (Table 1). Samples were applied with a respective remineralizing agent with the help of cotton tip applicator for 3 minutes twice daily, washed with deionized water and then stored in artificial saliva. All samples were placed in a universal incubator at $37^{\circ} \mathrm{C}$ between each remineralizing cycle. In the control groups, samples were only washed with deionized water and stored in artificial saliva. Artificial saliva (Moi Stir) was renewed every 24 hours.

After 10 cycles of remineralization, the surface microhardness of the specimens was determined using Vickers microhardness testing machine (Fig. 7). A load of $100 \mathrm{~g}$ was applied steadily to the surface of specimens for a period of 10s using Vickers elongated diamond pyramid indenter under a $\times 40$ objective lens. ${ }^{12}$ The accuracy of values of diagonal length of indentations was determined

Table: 1 Details of product

\begin{tabular}{lll}
\hline Product & Manufacturer & Composition \\
\hline Aclaim & $\begin{array}{l}\text { Aclaim } \\
\text { pharmaceuticals, } \\
\text { Bengaluru, India }\end{array}$ & $\begin{array}{l}1 \% \\
\text { Nano hydroxyapaptite }\end{array}$ \\
GC tooth mousse & Recaldent & $\begin{array}{l}10 \% \text { calcium } \\
\text { phosphopeptide - } \\
\text { amorphous calcium } \\
\text { phosphate (CPP-ACP) }\end{array}$ \\
$\begin{array}{l}\text { Colgate sensitive } \\
\begin{array}{l}\text { clove essence } \\
\text { toothpaste }\end{array}\end{array}$ & Colgate company & $\begin{array}{l}\text { Potasium nitrate } \\
\text { Clove oil }\end{array}$ \\
\hline
\end{tabular}

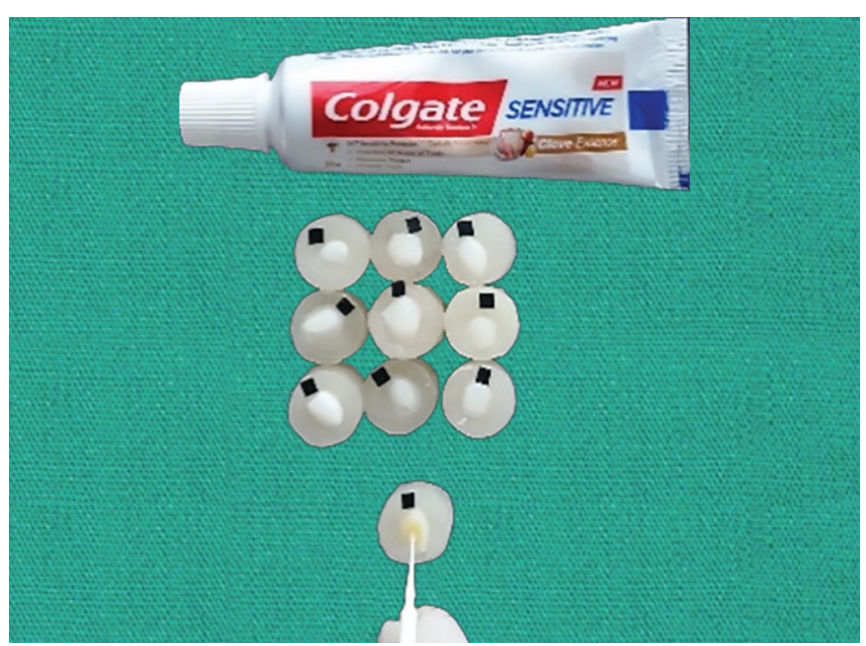

Fig. 6: Remineralization with potassium nitrate paste

under high power magnification of $\times 400$. The depth of the indentations was measured, and the values were converted to Vickers microhardness values. Five indentations were placed on the surface and the mean value was considered for each specimen.

\section{STATISTICAL ANALYSIS}

One-way ANOVA test, Tukey simultaneous comparison test was done for statistical analysis. One-way ANOVA test showed there has been an overall statistically significant difference between the demineralized and remineralized samples with a p-value less than 0.001 (Table 2). It also showed there is difference in mean values between the groups. Tukey's comparison test has been used for experimental groups to compare group's mean (Table 3). (compared with each other) are different (Graph 1).

Of all the groups the group in which no treatment was done showed the highest microhardness value. The statistical analysis was done comparing the experimental groups. To examine the difference post hoc test was done. Group 5 (HA) showed highest microhardness when compared with

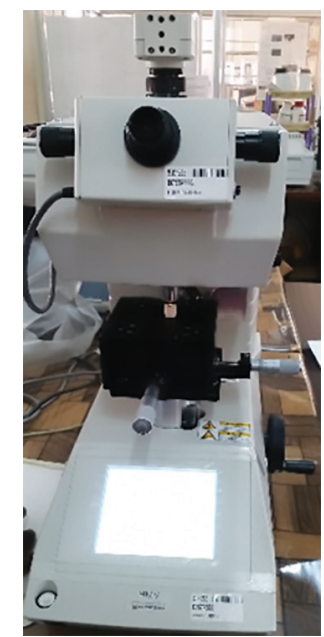

Fig. 7: Microhardness testing machine 


\begin{tabular}{|c|c|c|c|c|c|}
\hline \multicolumn{6}{|c|}{ Table 2: ANOVA test } \\
\hline \multicolumn{6}{|c|}{ One factor ANOVA } \\
\hline & Mean & $n$ & Std. dev & & \\
\hline & 304.0173 & 10 & 6.21974 & Group 2 & \\
\hline & 306.1380 & 10 & 6.72149 & Group 3 & \\
\hline & 324.1812 & 10 & 32.38933 & Group 4 & \\
\hline & 350.2408 & 10 & 23.53393 & Group 5 & \\
\hline & 321.1443 & 40 & 27.23333 & Total & \\
\hline \multicolumn{6}{|c|}{ ANOVA table } \\
\hline Source & SS & $d f$ & $M S$ & $F$ & $p$-value \\
\hline Treatment & $13,743.52243$ & 3 & $4,581.174142$ & 10.86 & 0.000 \\
\hline Error & $15,181.00433$ & 36 & 421.694565 & & \\
\hline Total & $28,924.52675$ & 39 & & & \\
\hline \multicolumn{6}{|c|}{ Table 3: Tukey's simultaneous test } \\
\hline \multicolumn{6}{|c|}{ Post-hoc analysis } \\
\hline \multicolumn{6}{|c|}{ Tukey simultaneous comparison $t$-values $($ d.f. $=36$ ) } \\
\hline & & Group 2 & Group 3 & Group 4 & Group 5 \\
\hline & & 304.0173 & 306.1380 & 324.1812 & 350.2408 \\
\hline Group 2 & 304.0173 & & & & \\
\hline Group 3 & 306.1380 & 0.23 & & & \\
\hline Group 4 & 324.1812 & 2.20 & 1.96 & & \\
\hline Group 5 & 350.2408 & 5.03 & 4.80 & 2.84 & \\
\hline \multirow{2}{*}{\multicolumn{6}{|c|}{$\begin{array}{cc}\text { Critical values for experiment wise error rate } \\
0.05 & 2.70\end{array}$}} \\
\hline & & & & & \\
\hline & & 0.01 & 3.35 & & \\
\hline
\end{tabular}

group 4 (CCP-ACP) and group 3 (potassium nitrate) and showed the highest microhardness. Groups 3 and 4 also showed statistically significant values in which group 4 (CCP-ACP) performed better compared to group 3.

\section{RESULTS}

The result showed there has been statistically significant difference in the microhardness for control samples and experimental samples. Within the experimental samples group which used hydroxyapatite paste as remineralizing paste showed better results than compared to paste which contain calcium and potassium ions and sodium nitrate (Graph 1).

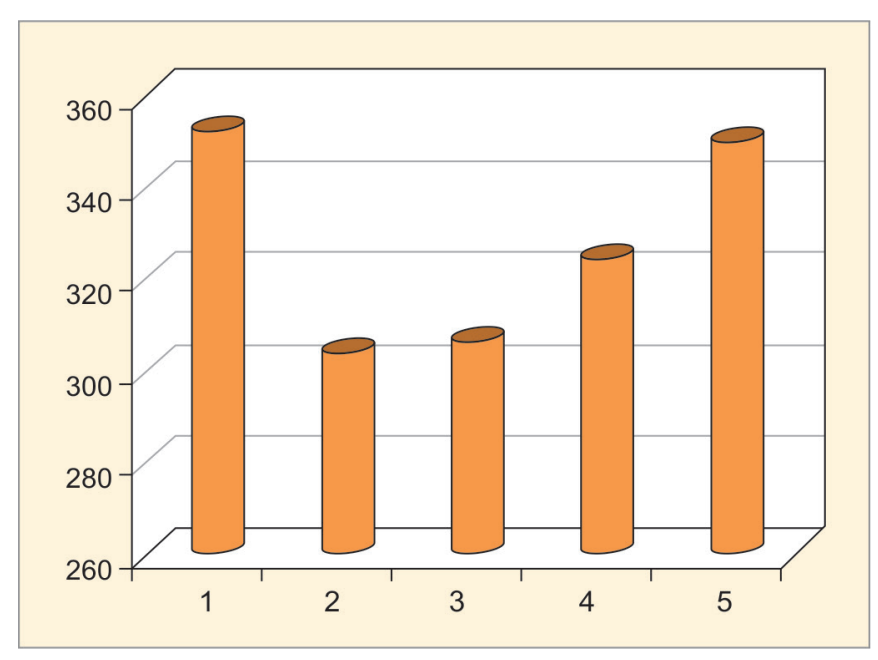

Graph 1: Results chart

\section{DISCUSSION}

This study highlights the remineralization effects of different toothpaste on demineralized enamel of extracted teeth. Dairy products such as milk and milk products like milk concentrates, powders, and cheeses have been demonstrated to have anti-cariogenic properties. ${ }^{9,10}$ In previous studies on rats have shown that a soluble form of casein or caseinate has the ability to reduce caries in rats. ${ }^{11}$ However, for effective caries control, huge amount was necessary, and that form of casein was not commercially ideal. ${ }^{12}$ The major tryptic peptide which has the anti-cariogenic nature of casein is casein phosphopeptides (CPP). Thus multiple phosphoseryl residues, CPP can stabilize calcium phosphate in a CPP-amorphous calcium phosphate (ACP) complex. ${ }^{12,13}$

Special milk-derived protein is present in recaldent called casein phosphopeptide (or CPP), and it carries calcium and phosphate ions in the form of amorphous calcium phosphate (ACP). This delivery system has bio-available calcium and phosphate ions, as a remineralizing ingredient that strengthens teeth ${ }^{12,13}$

Although the paste supplies calcium and phosphate ions for remineralization the microhardness was less than compared to nano hydroxyapatite paste. According to Galbiatti et al. following CCP-ACP application non-homogeneous deposits with adherent irregularities were formed and gets deposited as globular structures. These globular structures fill the interprismatic cavities and partially cover the prisms. ${ }^{14}$ 
Recently more studies are on biomimetic oral health products comprising of nano-sized hydroxyapatite particles. This manmade nano-hydroxyapatite (nHAP) has chemical-physical properties similar to the apatite structure within enamel, making it an interesting ingredient for oral health compounds. ${ }^{15}$ Studies have shown that this nHAP have a strong affinity to the tooth, and can get strongly adsorbed to enamel surfaces. ${ }^{15}$

Aclaim toothpaste contains nanoparticles of hydroxyapatite which is similar to natural hydroxyapatite of tooth. It was found to penetrate deeper into dentinal tubules and forms biomimetic apatite crystals on the dentin surface for additional protection. It was found to fill microcracks of enamel and helps in remineralization. Similar results were found in a study conducted by Najibfard et al. and he concluded that dentifrices containing nHAP have the potential for the same remineralizing capacity as a fluoride dentifrice and may be employed as an effective alternative to fluoride-containing dentifrices. ${ }^{16}$

According to Hannig et al. growth of organized, nanoapatite-based coatings closely resemble the hierarchical architecture of human enamel. ${ }^{16}$ Singh et al. studied the efficiency of four dentifrices which are Aclaim (n-HAP), Apagard (n-HAP), Clinpro Tooth Crème (tricalcium phosphate and fluoride), and Colgate Total (fluoride) to inhibit demineralization adjacent to orthodontic brackets. His study found out that the efficiency of aclaim and Apagard remineralizing pastes were found to be superior ${ }^{17,18}$ when compared with other toothpaste.

Nano hydroxyapatite has affinity to water which aid in wetting character that is capable of producing a thin but tightly bound layer on the tooth surface. ${ }^{19}$ This results in a high surface hardness of enamel. Ebadifar et al. in his study found out that fluoridated toothpaste can remineralize initial carious lesions. He also noted the synergistic effect when nanohydroxyapaite and fluoride toothpaste were used together in remineralization. ${ }^{20}$

Clove oil belongs to class of essential oils, extracted from the clove plant called Syzygiumaromaticum. It has health benefits and is also used in the production of perfume. Clove oil contains eugenol, acetyl eugenol, caryophyllene, and other compounds. Eugenol has many benefits, and it's been used as an antiseptic and anesthetic agent. This compound is contained in many dentistry products and used as a flavoring for medicines. Combination of clove oil with potassium nitrate in this new toothpaste offers everyday protection to the rampant sensitivity issues.

The mode of action of potassium nitrate is that the potassium ions enter the tubules and block the nerves of the pulp. It blocks A-fibers where repolarization of these fibers is prevented after initial depolarization. The potassium levels block the action potential generated in the intradental nerves. If potassium nitrate is kept in high concentration the depolarized state decreases the perception of pain. It acts as a numbing effect on dentin hypersensitivity. Although in Colgate sensitive clove essence potassium nitrate and clove oil are present it didn't enhance any remineralizing property. This could be the reason for less microhardness than compared to hydroxyapatite and $\mathrm{CCP}-\mathrm{ACP}$ paste.

Andréia Mara Andrade Pizani et al. studied the effect of different bleaching agent on microhardness of teeth. He concluded that the agent which contained calcium and potassium nitrate had better property than with the bleaching agent without calcium. ${ }^{21}$

Studies have reported more or comparable remineralizing effects for nanohydroxyapatite toothpastes in comparison to other toothpastes containing fluoride and CCP-ACP but not on potassium nitrate alone.

\section{CONCLUSION}

Remineralizing paste has various applications in dentistry. It can be used in primary teeth where there is a high risk of caries, as a preventive regimen to prevent caries for patients on chemotherapeutic treatment. It can also be used as a part of minimal intervention therapy in the early white lesion, prophylactic for orthodontic cases, erosive lesions, reducing dentin hypersensitivity.

From the present study, it was found the samples in which toothpaste containing hydroxyapatite showed better remineralizing than other two pastes. ${ }^{22}$

Even though potassium nitrate widely used in reducing dentin hypersensitivity, it cannot show any remineralizing property.

\section{CLINICAL SIGNIFICANCE}

Due to change in lifestyle and dietary habits, there is increase in incidence of caries in young children and adults. The balance of remineralization and demineralization will determine the non-cavitated caries lesion. With diet counseling, diet modifications and judicious use of remineralizing paste, caries can be prevented.

\section{REFERENCES}

1. Ricketts PD. Book reviews Dental Caries: The Disease and its Clinical Management 3rd edn. Fejerskov O, Nyvad B and Kidd EAM, eds. Oxford: Wiley/Blackwell, 2015 Dental Update [Internet]. Mark Allen Group; 2015 Nov 2;42(9):855-855.

2. Zafar S, Harnekar SY, Siddiqi A. Early childhood caries: etiology, clinical considerations, consequences and management. Int Dent SA. 2009;11(4):24-36.

3. Xu HH, Smith DT, Jahanmir S, Romberg E, Kelly JR, Thompson VP, Rekow ED. Indentation damage and mechanical proper- 
ties of human enamel and dentin. Journal of dental research. 1998 Mar;77(3):472-480.

4. Mehta R, Nandlal B, Prashanth S. Comparative evaluation of remineralization potential of casein phosphopeptideamorphous calcium phosphate and casein phosphopeptideamorphous calcium phosphate fluoride on artificial enamel white spot lesion: An in vitro light fluorescence study. Indian Journal of Dental Research. 2013 Nov 1;24(6):681-689.

5. Mehta R, Nandlal B, Prashanth S. Comparative evaluation of remineralization potential of casein phosphopeptideamorphous calcium phosphate and casein phosphopeptideamorphous calcium phosphate fluoride on artificial enamel white spot lesion: An in vitro light fluorescence study. Indian Journal of Dental Research. 2013 Nov 1;24(6):681-689.

6. Reynolds EC. Calcium phosphate-based remineralization systems: scientific evidence?. Australian dental journal. 2008 Sep;53(3):268-273.

7. Zhang Q, Zou J, Yang R, Zhou X. Remineralization effects of casein phosphopeptide-amorphous calcium phosphate crème on artificial early enamel lesions of primary teeth. International journal of Paediatric dentistry. 2011 Sep 1;21(5):374-381.

8. Somasundaram P, Vimala N, Mandke LG. Protective potential of casein phosphopeptide amorphous calcium phosphate containing paste on enamel surfaces. Journal of conservative dentistry: JCD. 2013 Mar;16(2):152-158.

9. Stookey GK. The Featherstone laboratory $\mathrm{pH}$ cycling model: a prospective, multi-site validation exercise. American journal of dentistry. 2011 Oct 1;24(5):322-328.

10. Secilmis A, Dilber E, Ozturk N, Yilmaz FG. The effect of storage solutions on mineral content of enamel. Materials Sciences and Applications. 2013 Jun 28;4(07):439-445.

11. Clark SE. Remineralization effectiveness of MI Paste Plus-a clinical pilot study. 2011.

12. Reynolds EC, Johnson IH. Effect of milk on caries incidence and bacterial composition of dental plaque in the rat. Archives of Oral Biology. 1981 Jan 1;26(5):445-451.

13. Colombo M, Beltrami R, Rattalino D, Mirando M, Chiesa M, Poggio C. Protective effects of a zinc-hydroxyapatite tooth- paste on enamel erosion: SEM study. Annali di stomatologia. 2016 Jul;7(3):38-45.

14. Carvalho FG, Brasil VL, Silva Filho TJ, Carlo HL, Santos RL, Lima BA. Protective effect of calcium nanophosphate and CPP-ACP agents on enamel erosion. Brazilian oral research. 2013 Dec;27(6):463-470.

15. Najibfard K, Ramalingam K, Chedjieu I, Amaechi BT. Remineralization of early caries by a nano-hydroxyapatite dentifrice. Journal of Clinical Dentistry. 2011 Jan;22(5):139.

16. Hannig M, Hannig C. Nanotechnology and its role in caries therapy. Advances in dental research. 2012 Sep;24(2): 53-57.

17. Llena C, Leyda AM, Forner L. CPP-ACP and CPP-ACFP versus fluoride varnish in remineralisation of early caries lesions. A prospective study. Eur J Paediatr Dent. 2015 Sep 1;16(3):181-186.

18. Singh A, Shetty B, Mahesh CM, Reddy VP, Chandrashekar BS, Mahendra S. Evaluation of efficiency of two nanohydroxyapatite remineralizing agents with a hydroxyapatite and a conventional dentifrice: A comparative In vitro study. Journal of Indian Orthodontic Society. 2017 Apr 1;51(2):92.

19. Singhal RK, Rai B. Remineralization Potential of Three Tooth Pastes on Enamel Caries. Open access Macedonian journal of medical sciences. 2017 Aug 15;5(5):664-666.

20. Ebadifar A, Nomani M, Fatemi SA. Effect of nano-hydroxyapatite toothpaste on microhardness ofartificial carious lesions created on extracted teeth. Journal of dental research, dental clinics, dental prospects. 2017;11(1):14.

21. Pizani AM, Tholt B, Paciornik S, Dias KR, Albuquerque PP, Queiroz CS. Dental bleaching agents with calcium and their effects on enamel microhardness and morphology. Brazilian Journal of Oral Sciences. 2015 Jun;14(2):154-158.

22. Orsini G, Procaccini M, Manzoli L, Giuliodori F, Lorenzini A, Putignano A. A double-blind randomized-controlled trial comparing the desensitizing efficacy of a new dentifrice containing carbonate/hydroxyapatite nanocrystals and a sodium fluoride/potassium nitrate dentifrice. Journal of clinical periodontology. 2010 Jun;37(6):510-517. 